\title{
BMJ Open Unemployment in the teens and trajectories of alcohol consumption in adulthood
}

\author{
Pekka Virtanen, ${ }^{1,2}$ Tomi Lintonen, ${ }^{3}$ Hugo Westerlund, ${ }^{4}$ Tapio Nummi, ${ }^{5}$ \\ Urban Janlert, ${ }^{2}$ Anne Hammarström ${ }^{2}$
}

To cite: Virtanen $P$, Lintonen $\mathrm{T}$, Westerlund $\mathrm{H}$, et al. Unemployment in the teens and trajectories of alcohol consumption in adulthood. BMJ Open 2016;6:e006430. doi:10.1136/bmjopen-2014006430

- Prepublication history for this paper is available online. To view these files please visit the journal online (http://dx.doi.org/10.1136/ bmjopen-2014-006430).

Received 22 June 2015 Revised 4 September 2015 Accepted 21 October 2015

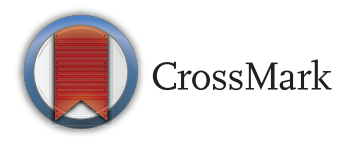

${ }^{1}$ University of Tampere, Institute for Advanced Social Research and School of Health Sciences, Tampere, Finland

${ }^{2}$ Department of Public Health and Clinical Medicine, Umeå University, Umeå, Sweden

${ }^{3}$ The Finnish Foundation for Alcohol Studies, Helsinki, Finland

${ }^{4}$ University of Stockholm, Stress Research Centre, Stockholm, Sweden

${ }^{5}$ University of Tampere, School of Health Sciences, Tampere, Finland

Correspondence to Dr Pekka Virtanen; pekka.j.virtanen@uta.fi

\section{ABSTRACT}

Objectives: The unemployed are assumed to adopt unhealthy behaviours, including harmful use of alcohol. This study sought to elucidate the relations between unemployment before age 21 years and consumption of alcohol from 21 to 42 years. The design was based on the conception of youth as a sensitive period for obtaining 'drinking scars' that are visible up to middle age.

Setting: The Northern Swedish Cohort Study has followed up a population sample from 1981 to 2007 with five surveys.

Participants: All pupils ( $n=1083$ ) attending the last year of compulsory school in Lulea participated in the baseline survey in classrooms, and 1010 of them (522 men and 488 women) participated in the last follow-up survey that was conducted at classmate reunions or by post or by phone.

Outcome measure: The trajectory of alcohol consumption from 21 to 43 years, obtained with latent class growth analyses, was scaled.

Results: Men were assigned to five and women to three consumption trajectories. The trajectory membership was regressed on accumulation of unemployment from 16 to 21 years, with multinomial logistic regression analyses. The trajectory of moderate consumption was preceded by lowest exposure to unemployment in men and in women. With reference to this, the relative risk ratios for high-level trajectory groups were 3.49 (1.25 to 9.79) in men and 1.41 ( 0.74 to 2.72 ) in women, but also the trajectories of low-level consumption were more probable (relative risk ratio 3.18 (1.12 to 9.02$)$ in men and 2.41 (1.24 to $4.67)$ in women).

Conclusions: High-level alcohol consumption throughout adulthood is, particularly among men, partly due to 'scars' from youth unemployment, particularly in men, but there are also groups of men and women where unemployment in the teens predicts a trajectory of low consumption.

\section{BACKGROUND}

A lot of research has been devoted to show that unemployment increases intake of alcohol, binge drinking and diagnosed

\section{Strengths and limitations of this study}

- This was a long (27 years) follow-up of a population cohort with virtually total participation in the surveys.

- Owing to the high participation rate, there was no drinking-related sample attrition.

- By virtue of breaking the average development down to trajectories, the study clarified and quantified the dual development: exposure to youth unemployment increases the probability of both high and low-level consumption of alcohol in adulthood.

- The findings may be limited to Sweden and similar societies.

alcohol use disorders. ${ }^{1-4}$ The research is based on the theoretical reasoning that losing one's job and being jobless may be accompanied by conditions-for example, increased distress, worsening mental health, feelings of frustration and shame, loss of structures of daily life and tensions in family and other social relations-that predispose individuals to increase their drinking. ${ }^{2}$ There are findings supporting this logic, but the evidence of unemployment as a cause of drinking seems to be less consistent than the evidence of drinking as a cause of unemployment. ${ }^{3}$ Therefore, it is reasonable to assume that there are also conditions that may decrease drinking: in addition to reduced income, unemployment means, in any case, lack of job-related stress and also, in some cases, distance from the 'wet' culture represented by workmates. Indeed, working seems to be associated with high consumption, at least in adolescence. ${ }^{5}$

Unemployment is quite common around the entry to work life. ${ }^{6} 7$ Partly, periods of youth unemployment may be considered as transient and relatively unimportant friction in the attachment to the labour market. On the other hand, unemployment in the teens 
may be deleterious, because it occurs during a phase of the life course that is important for the development of independence and identity of an individual. In addition to-and also due to-causing lifelong 'wage penalties, ${ }^{8}$ and permanent 'scars' in the labour market attachment and employability, ${ }^{9}$ unemployment during this sensitive period may leave 'scars', in terms of socialisation, and a lifestyle of risky health behaviours, as well as in terms of lowered mental well-being and may ultimately harm somatic health. In this context, the relation of youth unemployment with alcohol consumption in adulthood poses an essential question.

A study ${ }^{10}$ that followed up 17-19-year-old Norwegians for 3 years found that exposure to unemployment was not associated with alcohol consumption (measured as cl of pure alcohol in 1 year) when controlling for the intake at baseline. In contrast, a study from the USA showed that being heavy drinker (consuming more than five drinks on one occasion) at the age of 27-35 years was associated with exposure to unemployment during the preceding 12-year period ${ }^{11}$ According to a British study among men, ${ }^{12}$ the association of high-alcohol consumption at the age of 33 years (belonging to the top fifth) with unemployment experienced between the ages 16 to 33 years was non-significant, whereas unemployment during the preceding year was associated with heavy drinking.

The present study is based on a 26-year follow-up of the Northern Swedish Cohort. ${ }^{13}$ An early study with the cohort $^{14}$ found that, both among men and women, those exposed to unemployment for more than 20 weeks at age 16-21 years consumed more alcohol at 21 years, compared with those having less or no exposure. The associations between exposure and consumption remained significant after adjustments for consumption at 16 years and a set of socioeconomic factors. In the study based on follow-up until the age of 30 years, ${ }^{15}$ the participants were classified intoan early unemployment group (unemployed over 6 months between the ages of 16 and 21 years, irrespective of later unemployment), the late unemployment group (unemployed over 18 months between the ages of 22 and 30 years and unemployed less than 6 months between the ages of 16 and 21 years) and the reference group consisting of those who did not fulfil these criteria. A dichotomous measure (split at 75 th centile, separately for men and women) was used as indicator of high consumption of alcohol versus none. Throughout the follow-up, the figures for high consumption were greatest in the early unemployment groups. After adjusting for consumption at baseline, however, neither in the early nor late unemployment group did the probability of being a high consumer at the age of 30 years differ significantly from the reference group.

In this study, we were asking how exposure to unemployment in the 1980s, when participants of the Northern Swedish Cohort were in their teens, is reflected in their consumption of alcohol in the 1990s and in the 2000s, up to the age of 42 years. Our hypothesis was that, in spite of the non-significant findings of the previous study, an analysis based on longer-term follow-up and identification of longitudinal patterns of consumption would reveal that youth unemployment predicts high consumption in adulthood both among men and women.

\section{DATA AND VARIABLES}

The Northern Swedish Cohort Study was set up in 1981 with a questionnaire to all pupils $(\mathrm{n}=1083)$ who attended the last year of compulsory school (age 16 years) in all nine schools in a middle-sized municipality in Northern Sweden. Follow-up surveys were conducted in 1983 (age 18 years), 1987 (age 21 years), 1995 (age 30 years) and 2007 (age 42 years). The response rates were very high: at the 26-year follow-up in 2007, a total of 522 men and 488 women $(n=1010,94 \%$ of those still alive) continued to participate.

The baseline survey took place in classrooms. The questionnaire contained queries on somatic and mental health, family background, school performance and environment and, as part of health-related behaviours, the use of alcohol. The pupils were asked to rate their consumption of alcohol as frequency of drinking occasions and average intake of beer (number of bottles), wine (number of glasses) and strong beverages (number of drinks) on each occasion. This question on alcohol use was included in subsequent surveys that took place at classmate reunions, and those who did not attend were surveyed by post or by telephone.

The questionnaire at 18 years of age included a question about total duration of unemployment in months during the previous 2 years, that is, since the end of compulsory school. The principal investigator $(\mathrm{AH})$ conducted personal interviews about length of unemployment at the follow-ups at 18 and 21 years with all those who had been unemployed during the period. In the questionnaire at 21 years, there was a matrix that consisted of columns representing spring semester, summer and autumn semester during the previous 3 years, and rows representing different labour market positions. If the respondent marked only the position 'unemployed', he or she was classified as having been unemployed for the whole 6-month period; if there were, in addition, some other position(s), the number of unemployment months was obtained by dividing duration of the period by number of options. Values of the periods plus the values for ages 16 to 18 years were then summed into the variable 'months of youth unemployment'.

The 1981 survey included questions regarding the occupation of the mother and the father of the respondent. Applying the Swedish classification system, ${ }^{16}$ the occupation of each parent was classified into social group 1 (including entrepreneurs and higher whitecollar workers), social group 2 (including lower white collar workers) and social group 3 (including manual 
and non-manual workers). The parental social class was defined as having no, one or two parents from social group 3. The question about somatic and mental health of the father and mother specified alcoholism as one of the health problems; the replies were combined into a 'parental alcoholism' variable.

Truancy at 16 years of age was included in the analyses as an indicator of externalised behaviour. Replies to the five-option question about absence from school without illness or after asking for and having been granted permission were dichotomised as never/a few times in a semester.

\section{Measures of alcohol consumption}

Reported amounts and frequencies of intake of beverages were calculated into yearly average intake in centilitres of absolute alcohol at 21, 30 and 42 years, which was then used to construct two different variables of alcohol consumption. First, heavy drinking at the 21, 30 and 42 years was defined as belonging to the upper consumption quartile, separately for men and women. Second, heterogeneity in the longitudinal development of the consumption from 21 to 42 years was analysed by latent class growth analysis. ${ }^{17} 18$ The consumption trajectories were identified using the Flexmix package ${ }^{19}$ in $\mathrm{R}$ statistical software. First degree polynomial (linear) models were fitted and prior probabilities estimated using the method of maximum likelihood. The Bayesian Information Criteria (BIC) suggested three trajectories for women and five trajectories for men as preferred solutions.

Among women (figure 1), $47 \%$ were assigned to the trajectory characterised by steady 'moderate level' consumption throughout the follow-up. The group members comprising $31 \%$ of women were 'high level' consumers already at the baseline and slightly increased
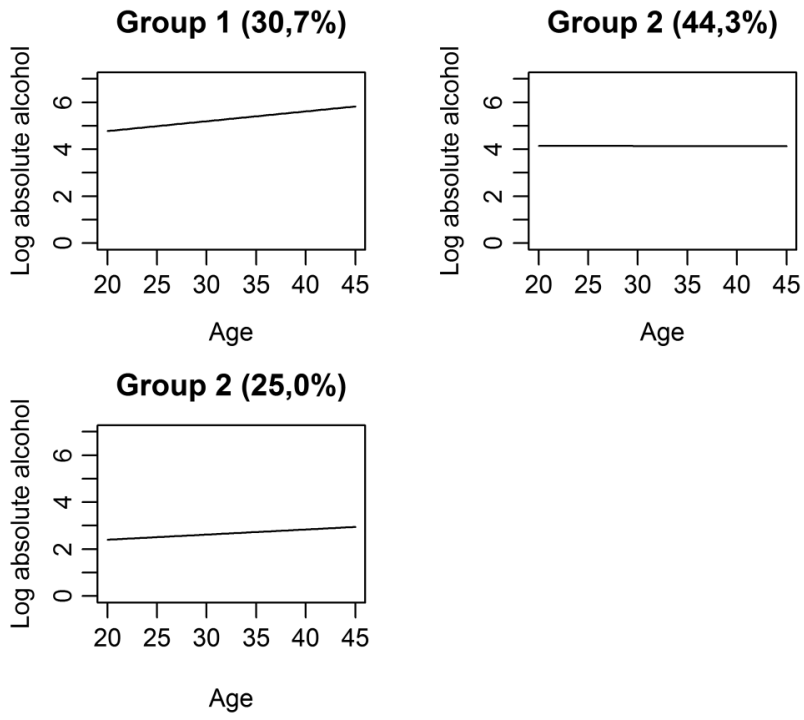

Figure 1 Illustrations of the trajectories of alcohol consumption from 21 to 42 years among women $(n=488)$ of the Northern Swedish Cohort. consumption by age, and $22 \%$ of women were assigned to the 'low level' trajectory.

Among men (figure 2), about half were assigned either to the 'high level' (27\%) or to the 'increasing to high level' (22\%) trajectory group, the former showing a slight decline of consumption, while among the latter the consumption at the end of the follow-up was highest of all. The other half of men was distributed evenly to the 'low level' trajectory (18\%), the 'increasing to moderate level' trajectory $(16 \%)$ and the 'decreasing to moderate level' trajectory $(17 \%)$.

\section{Statistics}

The distribution of alcohol consumption was highly skewed to the right, and therefore $\log$ transformed values of the yearly alcohol consumption were used in analyses of the drinking trajectories, as well as in adjusting for the baseline consumption (age 16 years), and the regression analyses between youth unemployment and adult drinking. Binary logistic regressions were used in analysing the associations of youth unemployment with heavy drinking at different ages, and multinomial logistic regressions in analysing its associations to the trajectories. In addition to baseline consumption, the analyses were adjusted for truancy, and social class and alcoholism of the parents. Since the identified trajectories are based on posterior probabilities, the regression analyses were weighted with the probability used (ie, highest one) when assigning individuals to the identified trajectories.

\section{RESULTS}

Associations of youth unemployment with adulthood heavy drinking

High exposure to youth unemployment predicted heavy drinking at 21 years, in men and in women (table 1), independently of being a heavy drinker at baseline. At 30 years, the association was statistically non-significant even in the unadjusted analysis among men. Among women, the OR was non-significant after adjustments. By 42 years, the associations of youth unemployment with heavy drinking were still non-significant, and in men the OR had even dropped below unity (to 0.91 in the unadjusted and 0.94 in the adjusted model).

\section{Associations of youth unemployment with adulthood drinking trajectory}

The trajectory group with lowest average exposure to youth unemployment was chosen as the reference in the multinomial logistic regressions. The analyses showed that women on the 'Moderate level' and men on the 'Increasing to moderate level' trajectory were the least exposed. The tables were constructed with these groups in the left column, and the rest of the columns were arranged in the order of increasing average exposure to youth unemployment of the trajectory group. 
Figure 2 Illustrations of the trajectories of alcohol consumption from 21 to 42 years among men $(n=522)$ of the Northern Swedish Cohort.
Group $1(16,4 \%)$

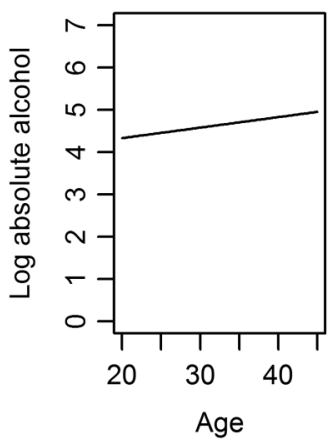

Group $4(17,8 \%)$

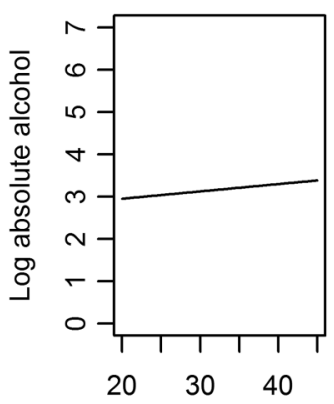

Age
Group $2(26,9 \%)$
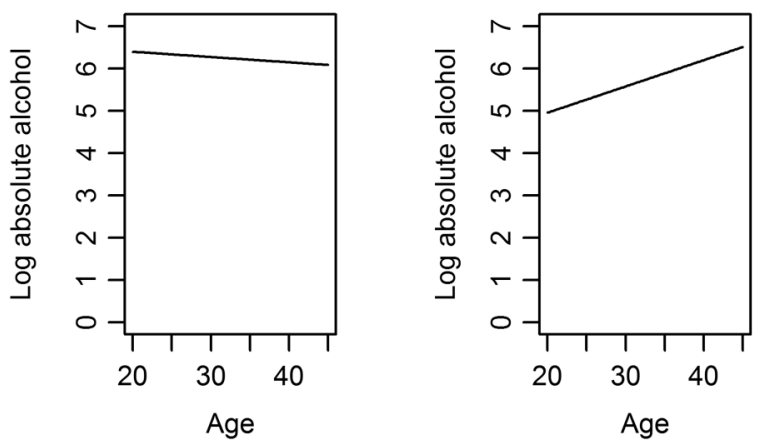

Group $5(16,6 \%)$

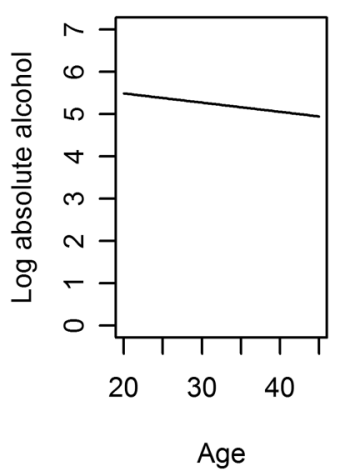

\section{Women}

The findings for women are displayed in table 2. The reference group with 'Moderate level' consumption trajectory had on the average been exposed to 2.40 months to youth unemployment. The exposure was highest (3.54 months) in the group assigned to the 'Low level' trajectory. ORs showed the difference between the 'High level' and the 'Moderate level' trajectory groups as nonsignificant, while the difference between the 'Low level' and the 'Moderate level' groups was significant. Moreover, in case of the comparison between low and moderate level, the OR grew when consumption at baseline was added to the model.

\section{Men}

Among men, the average exposure to youth unemployment ranged from 5.43 months in the 'High level' group to 1.34 months in the group with 'Increasing to moderate level' consumption trajectory (table 3).
The trajectory of the groups 'Increasing to high level' and 'Decreasing to moderate level' did not differ significantly from the reference group, whereas the ORs showed the 'Low level' and 'High level' trajectory groups as significantly different. Overall, the ORs dropped after adjustments but the result pattern, as well as statistical significance of the findings, remained unchanged.

\section{DISCUSSION}

According to earlier studies of the Northern Swedish Cohort, high exposure to unemployment is associated with high-alcohol consumption among youth, ${ }^{14}$ but youth unemployment does not have an independent long-term effect on heavy consumption at 30 years. ${ }^{15}$ In the present study, we set out to analyse in more detail the potential scarring effects of youth unemployment on alcohol consumption during the life course, by utilising the longer follow-up until 42 years and trajectory analyses. As a kind of baseline analysis, we replicated the

Table 1 Associations (ORs and 95\% Cls) between exposure to unemployment between the ages of 16 and 21 years and heavy consumption of alcohol (being in the upper quartile) at the ages of 21, 30 and 42 years, in men and women

\begin{tabular}{|c|c|c|c|c|}
\hline \multirow[b]{2}{*}{ Age (years) } & \multicolumn{2}{|l|}{ Men } & \multicolumn{2}{|l|}{ Women } \\
\hline & Unadjusted & Adjusted* & Unadjusted & Adjusted* \\
\hline 21 & 2.47 (1.69 to 3.60$)$ & 2.04 (1.36 to 3.07$)$ & 2.22 (1.36 to 3.62$)$ & $1.82(1.07$ to 3.10$)$ \\
\hline 30 & $1.29(0.91$ to 1.83$)$ & $1.21(0.83$ to 1.78$)$ & 1.71 (1.05 to 2.79$)$ & 1.53 (0.91 to 2.58$)$ \\
\hline 42 & $0.91(0.61$ to 1.37$)$ & $0.94(0.61$ to 1.44$)$ & $1.14(0.69$ to 1.89$)$ & $1.04(0.60$ to 1.81$)$ \\
\hline
\end{tabular}

${ }^{\star}$ Adjusted for social class and alcoholism of the parent(s) and for alcohol consumption and truancy at baseline (age 16 years).

Bold typeface represents statistical significance $(p<0.05)$. 
Table 2 Exposure to youth unemployment (from 16 to 21 years) and alcohol consumption trajectories from 21 to 42 years in women

\begin{tabular}{|c|c|c|c|}
\hline & \multicolumn{3}{|c|}{ Consumption trajectory } \\
\hline & $\begin{array}{l}\text { Moderate level } \\
\mathrm{n}=224\end{array}$ & $\begin{array}{l}\text { High level } \\
n=150\end{array}$ & $\begin{array}{l}\text { Low level } \\
n=106\end{array}$ \\
\hline Months of youth unemployment (mean) & 2.40 & 3.15 & 3.54 \\
\hline OR $(95 \% \mathrm{CI})^{*}$ & ref & $1.49(0.82$ to 1.71$)$ & $1.87(1.02$ to 3.40$)$ \\
\hline OR $(95 \% \mathrm{Cl}) \dagger$ & ref & $1.72(0.93$ to 2.20$)$ & 1.89 (1.01 to 3.55$)$ \\
\hline OR $(95 \% \mathrm{Cl}) \ddagger$ & ref & 1.41 (0.74 to 2.72$)$ & 2.41 (1.24 to 4.67$)$ \\
\hline \multicolumn{4}{|c|}{$\begin{array}{l}\text { ORs with } 95 \% \text { Cls for belonging to the trajectory group in order of increasing exposure, that is, with zero exposure of the 'moderate level' } \\
\text { group as the reference. } \\
\text { ”Unadjusted. } \\
\text { †Adjusted for social class and alcoholism of the parent(s). } \\
\text { †Adjusted for ( } 2 \text { ) and alcohol consumption and truancy at baseline (age } 16 \text { years). } \\
\text { Bold typeface represents statistical significance }(p<0.05) \text {. }\end{array}$} \\
\hline
\end{tabular}

study of Hammarström and Janlert ${ }^{15}$ into the extended setting, and found that the effect of youth unemployment on heavy drinking continues attenuating up to middle age in both genders. Next, we broke down the population cohort into groups with different adulthood consumption trajectories and related them with exposure to youth unemployment. The results suggested that, among men with high-level consumption throughout the period from early adulthood to early middle age, part of the consumption may be due to 'scars' from youth unemployment. Among women assigned to the trajectory of high-level consumption, corresponding scarring was less evident. These findings support our hypothesis, at least in men. However, we also found 'inverse scarring': both among men and among women there were groups of considerable size that assumed low-level consumption trajectories in adulthood, in spite of having a history of relatively high exposure to youth unemployment.

The whole-cohort analysis is in line with the results of the British study, which found that heavy drinking was associated with recent but not with earlier exposure to unemployment. ${ }^{12}$ Results of the US study on heavy drinking as the outcome,${ }^{11}$ however, tends to contradict our findings by showing that there is an association between exposure to involuntary unemployment during teens and early adulthood on the one hand, and alcohol consumption in early middle age on the other.

In the trajectory analyses, we chose to use uncategorised consumption figures as the outcome. In this respect, the present study is similar to the earlier mentioned study from Norway, ${ }^{10}$ which, however, used average consumption whereas the outcome in our study was a spectrum of consumption trajectories. In the light of our results, the Norwegian finding, according to which exposure to unemployment in the teens does not predict consumption, can be understood as a mixture of differential associations. In other words, there seems to be a genuine dual association between unemployment and use of alcohol: among those exposed to youth unemployment there are both those with high and those with low consumption in adulthood. Therefore, conclusions drawn from analyses of average development may convey an overly uniform and simplified depiction of reality.

Use of the amount of alcohol-regardless of the pattern of consumption-as the outcome, is in line with the ideology of trajectory analysis, which is not to prefix

Table 3 Exposure to youth unemployment (from 16 to 21 years) and alcohol consumption trajectories from 21 to 42 years of age in men

\begin{tabular}{|c|c|c|c|c|c|}
\hline & \multicolumn{5}{|c|}{ Consumption trajectory } \\
\hline & $\begin{array}{l}\text { Increasing to } \\
\text { moderate level } \\
\mathrm{n}=86\end{array}$ & $\begin{array}{l}\text { Increasing to high } \\
\text { level } \\
n=133\end{array}$ & $\begin{array}{l}\text { Decreasing to } \\
\text { moderate level } \\
\mathrm{n}=95\end{array}$ & $\begin{array}{l}\text { Low level } \\
\mathrm{n}=84\end{array}$ & $\begin{array}{l}\text { High level } \\
n=117\end{array}$ \\
\hline $\begin{array}{l}\text { Months of youth } \\
\text { unemployment } \\
\text { (mean) }\end{array}$ & 1.34 & 1.86 & 2.40 & 4.16 & 5.43 \\
\hline OR $(95 \% \mathrm{CI})^{*}$ & ref & 1.56 (0.51 to 4.82$)$ & $2.21(0.73$ to 6.76$)$ & 3.76 (1.34 to 10.6$)$ & 4.85 (1.76 to 13.4$)$ \\
\hline OR $(95 \% \mathrm{Cl}) \dagger$ & ref & $1.53(0.49$ to 4.77$)$ & 2.11 (0.68 to 6.50$)$ & 3.73 (1.31 to 10.6$)$ & 5.02 (1.80 to 14.0$)$ \\
\hline OR $(95 \% \mathrm{Cl}) \ddagger$ & ref & $1.24(0.40$ to 3.86$)$ & $1.66(0.54$ to 5.13$)$ & 3.18 (1.12 to 9.02$)$ & 3.49 (1.25 to 9.79$)$ \\
\hline \multicolumn{6}{|c|}{$\begin{array}{l}\text { ORs with } 95 \% \text { Cls for belonging to the trajectory group in order of increasing exposure, that is, with zero exposure of the 'increasing to } \\
\text { moderate level' group as the reference. } \\
\text { *Unadjusted. } \\
\text { †Adjusted for social class and alcoholism of the parent(s). } \\
\text { †Adjusted for ( } 2 \text { ) and alcohol consumption and truancy at baseline (age } 16 \text { years). } \\
\text { Bold typeface represents statistical significance }(p<0.05) \text {. }\end{array}$} \\
\hline
\end{tabular}


or categorise the phenomenon of interest but, rather, to see what kind of trajectories the data include and to interpret them-in a sense, to tell associated 'developmental stories'. Moreover, we argue that, by virtue of using consumption as the outcome variable, the present study revealed phenomena that have remain undetected in analyses with problematic drinking (frequency of occasions, binge drinking, etc) as the outcome. Despite the different numbers of trajectories, we found that in both genders the trajectory groups associated with lowest youth unemployment have been characterised as drinking 'moderately'. In women, this group includes almost half of the cohort (44\%), while in men the proportion is smaller $(16 \%)$.

We included consumption and truancy at baseline in the analyses when the cohort was still attending compulsory school and had not yet been at risk of exposure to unemployment but was facing the entry to labour market-or to the market of post basic education. At this point of time in life, truancy can be seen as an indicator of relatively low interest and motivation to pursue further studies, as well as being a symptom of externalised behaviour. Some of the inherited risk for alcohol use disorders was taken into account with the parental alcoholism variable, and in line with the design of the study, we considered it more appropriate to control for the socioeconomic conditions by parental social class than by own occupational position attained during the follow-up. For similar reasons, we did not include adulthood unemployment in the multivariate models.

Our study revealed, on its part, a complexity of the associations between alcohol consumption and work life course. For instance, the trajectory group of men with 'increasing to high level' consumption had suffered relatively little from youth unemployment. This raises the question of consumption patterns: maybe these individuals tend to drink rather frequently, but small amounts on each occasion, and therefore can keep a stable labour market position. Moreover, we can question how far the low-level trajectory can be seen as an indicator of an advantageous life course: maybe these men and women are less socially active and therefore drink less, or they cannot afford to drink so much (especially to go out), and some might even abstain from drinking because they have had earlier problems with alcohol and believe that drinking could harm their chances in the labour market. The trajectories provide a novel starting point for future studies concerning 'disadvantaged low consumers', but also potential 'advantaged high consumers'.

The long follow-up time and high participation rate are evident strengths of our study. The sample also included those marginalised individuals with more severe alcohol abuse, and therefore the trajectories represent a real distribution of the population. Measurement of unemployment by a questionnaire, instead of register data, also can be considered a strength, as self-reported unemployment indicates that the unemployment experience has been significant. A limitation is that the findings may be considered locality specific, although it has been shown that the cohort in many respects is representative of the whole country. ${ }^{11}$ Western countries do not differ in the main structures of their educational systems: after compulsory school, some graduates enter into post basic education while others enter the labour market. With respect to this, our results can be generalised, although in Sweden, entry into education may be more common than in most other countries.

The present study is part of the research project 'Unemployment Scarring'. According to the scarring hypothesis, the behavioural changes that take place during unemployment do not change instantaneously at the end of unemployment, but restoration takes time and may remain incomplete over a long period of time. The nature of scars may be assumed to depend, in addition to the amount of exposure to unemployment, on the moment of exposure during the life course. The years of entry into the labour market may be a period of particular sensitivity for the consequences of unemployment $^{20}$ as well as for obtaining scars of unemployment. The scarring approach was also the reason we did not analyse potential differences in the strength of the associations between drinking and actual unemployment at different ages. This interesting question remains a topic for future research.

With respect to policy implications, measures that reduce youth unemployment might reduce the relatively large proportion (about half of the studied cohort) assuming high-level consumption in adulthood. Although the proportion of those assuming low-level drinking trajectories may also decrease, the net effect would probably be reduction of consumption and also of problematic use of alcohol.

Contributors PV conceived the study, participated in its design and drafted the manuscript. TL and HW participated in design of the study and interpretation of the results, and commented on the manuscript. TN participated in the design of the study, performed the trajectory analyses and drafted corresponding parts of the manuscript. UJ and AH conceived the study, participated in its design and coordination, and contributed to drafting of the manuscript. All the authors read and approved the final manuscript.

Funding The study has been financed by The Swedish Research Council for Environment, Agricultural Sciences and Spatial Planning dnr 259-2012-37 and by the Academy of Finland (grant number 132668).

Competing interests None declared.

Ethics approval Regional Ethical Review Board in Umeå, Sweden.

Provenance and peer review Not commissioned; externally peer reviewed.

Data sharing statement No additional data are available.

Open Access This is an Open Access article distributed in accordance with the Creative Commons Attribution Non Commercial (CC BY-NC 4.0) license, which permits others to distribute, remix, adapt, build upon this work noncommercially, and license their derivative works on different terms, provided the original work is properly cited and the use is non-commercial. See: http:// creativecommons.org/licenses/by-nc/4.0/ 


\section{REFERENCES}

1. Forcier M. Unemployment and alcohol abuse: a review. J Occup Environ Med 1988;30:246-51.

2. Henkel D. Unemployment and substance use: a review of the literature (1990-2010). Curr Drug Abuse Rev 2011;4:4-27.

3. de Goeij MC, Suhrcke M, Toffolutti V, et al. How economic crises affect alcohol consumption and alcohol-related health problems: a realist systematic review. Soc Sci Med 2015;131:131-46.

4. Paljärvi T, Martikainen P, Pensola T, et al. Life course trajectories of labour market participation among young adults who experienced severe alcohol-related health outcomes: a retrospective cohort study. PLOS ONE 2015;10:e0126215.

5. Kouvonen A, Lintonen T. Adolescent part-time work and heavy drinking in Finland. Addiction 2002;97:311-18.

6. Eurofound. Mapping youth transitions in Europe. Luxembourg: Publications Office of the European Union 2014. http://eurofound. europa.eu/publications/report/2014/labour-market/ mapping-youth-transitions-in-europe

7. Eurofound. Young people and temporary employment in Europe. Luxembourg: Publications Office of the European Union 2014. http:// eurofound.europa.eu/observatories/emcc/comparative-information/ young-people-and-temporary-employment-in-europe

8. Arulampalam $\mathrm{W}$. Is unemployment really scarring? Effects of unemployment experiences on wages. Econ $J$ 2001;111:585-606.

9. Eliasson M, Storrie D. Latent or lasting scars? Swedish evidence on the long-term effects of job displacement. J Labor Econ 2006;24:831-56
10. Hammer T. Unemployment and use of drug and alcohol among young people: a longitudinal study in the general population. $\mathrm{Br} J$ Addict 1992;87:1571-81.

11. Mossakowski KN. Is the duration of poverty and unemployment a risk factor for heavy drinking? Soc Sci Med 2008;67:947-55

12. Montgomery S, Cook D, Bartley M, et al. Substance abuse. Unemployment, cigarette smoking, alcohol consumption and body weight in young British men. Eur J Public Health 1998;8:21-7.

13. Hammarström A, Janlert U. Cohort profile: the Northern Swedish Cohort. Int J Epidemiol 2012;41:1545-52.

14. Janlert $U$, Hammarström A. Alcohol consumption among unemployed youths: results from a prospective study. $\mathrm{Br} \mathrm{J}$ Addict 1992;87:703-14.

15. Hammarström A, Janlert U. Early unemployment can contribute to adult health problems: results from a longitudinal study of school leavers. J Epidemiol Community Health 2002;56:624-30.

16. Statistics Sweden. Swedish socio-economic classification (in Swedish). Stockholm: Statistics Sweden, 1983.

17. Nagin D. Analyzing developmental trajectories: a semiparametric, group-based approach. Psychol Methods 1999;4:139-57.

18. Nagin D. Group-based modelling of development. London: Harvard University Press, 2005.

19. Leisch F. FlexMix: a general framework for finite mixture models and latent class regression in R. J Stat Softw 2004;11:1-18.

20. Reine I, Novo M, Hammarström A. Does the association between ill health and unemployment differ between young adults and adults? Results from a 14-year follow-up study with a focus on psychological health and smoking. Public Health 2004;118:337-45. 